九州大学学術情報リポジトリ

Kyushu University Institutional Repository

\title{
Ergonomic study for comfort operating the pedals of the agricultural tractors
}

Kim, Hyuck-Joo

National Academy of Agricultural Science, Rural Development Administration

Kim, Myoung-Ho

Department of Bio-Industrial Machinery Engineering, Chonbuk National University

Inoue, $\mathrm{E} \mathrm{i} \mathrm{j} \mathrm{i}$

Laboratory of Bioproduction Engineering, Division of Bioproduction Environmental Sciences, Department of Agro-environmental Sciences, Faculty of Agriculture, Kyushu University

Okayasu, Takashi

Laboratory of Bioproduction Engineering, Division of Bioproduction Environmental Sciences,

Department of Agro-environmental Sciences, Faculty of Agriculture, Kyushu University

他

https://doi.org/10.5109/27364

出版情報: 九州大学大学院農学研究院紀要. 58 (2)，pp.329-338，2013-09. Faculty of Agriculture， Kyushu University

バージョン :

権利関係 : 


\title{
Ergonomic study for comfort operating the pedals of the agricultural tractors
}

\author{
Hyuck-Joo KIM ${ }^{1}$, Myoung-Ho KIM², Eiji INOUE, \\ Takashi OKAYASU and Dae-Cheol KIM ${ }^{2 *}$
}

\author{
Laboratory of Bioproduction Engineering, Division of Bioproduction Environmental Sciences, \\ Department of Agro-environmental Sciences, Faculty of Agriculture, \\ Kyushu University, Fukuoka 812-8581, Japan \\ (Received April 26, 2013 and accepted May 9, 2013)
}

\begin{abstract}
Aging and feminization of farming population are a major burden on current agricultural sector, and some measures are demanding to adjust this trend. The agricultural mechanization has relieved farmers of most of the hard physical labor, but still work environments are poor, and there are a lot of harmful factors affecting human health. Therefore, improvement of safety and comfort in agricultural machinery is needed. In case of the most commonly used domestic agricultural machinery, agricultural tractors, operation device location and operating force are regulated by international rules such as ISO 4253, but the rule is not sufficient for domestic operators, since it was not developed for operator's comfort and was drawn out based on the westerners.

In this study, we developed a technique that evaluates the conformability of tractor driving operation device for all Korean farmers including senior and women farmers. We also established evaluation equipments and inspection method of tractor operation conformability to promote dissemination of tractors that suit for Korean farmers' physique. In the future, the result allows tractor manufacturers to propose design guidelines for proper location and operating force of tractor operating device. It also allows domestic agriculture manufacturers to develop agricultural machinery that considered the conformability of farmers from the design stage.
\end{abstract}

Key words: tractor, convenience, operating device, guideline, expediency

\section{INTRODUCTION}

Aging and feminization of farming population are a major burden on current agricultural sector, and some measures are demanding to adjust this trend. The aging (18.6\% , National Statistical Office, '05) and feminization (51.2\%, Ministry of Agriculture and Forestry, '05) of the farming population have increased the occurrence rate of farmer syndrome (42.7\%, '04 MAF), and the population of musculoskeletal disorders among farmers are 2.4 times higher than that among the non-farmers ('04 National Institute of Agricultural Science and Technology). Especially, the prevalence rate on back pain and shoulder pain of farmers are higher than other workers by $50 \%$ and $37 \%$, respectively. Therefore, supports for improving work environment and preventing agricultural disease are recommended. The agricultural mechanization has relieved farmers of most of the hard physical labor. However, there are still poor work environments and harmful factors affecting human health. Therefore, the development of agricultural machinery considering the body type of farmers is needed to improve safety and comfort.

To provide a comfortable work space for tractor drivers, ISO 4253 and ISO 15077 regulate the location of driv-

\footnotetext{
1 National Academy of Agricultural Science, Rural Development Administration, Suin-ro 150th, Suwon-si, Gyeonggi-do, 441707, Republic of Korea

Department of Bio-Industrial Machinery Engineering, Chonbuk National University, 567, Baekje-daero, Deokjin-gu, Jeonju-si, Jeollabuk-do, 561-756, Republic of Korea

* Corresponding Author (E-mail: dckim12@jbnu.ac.kr)
}

ing and operation device, and operating force. However, the rule was made to fit westerners, and it is not suitable for domestic drivers. In particular, Park et al., (2002) investigated the degree of inconvenience while using tractors, subjected to the domestic tractor drivers. The drivers responded only $67 \%$ in the pedal position, $79 \%$ in the gear shift lever, $84 \%$ in the handle height, and 52\% in the handle distance are suitable for use; and the authors recommended that ensuring convenience of the tractor is required. The current domestic manufacturers are mainly focusing on the work performance of tractors at the developing stage, and they do not consider the tractor drivers' comfort while driving. Therefore, a device which evaluates the comfort of tractor operating is needed to be developed for all Koreans farmers including women and senior farmers. This study intends to establish an evaluation method and inspection criteria of comfort for Korean farmers. By providing the result as a guideline for tractor design, encourage the domestic agricultural manufacturers to develop agricultural machinery with the convenience of the Korean farmers in consideration.

In this study, we have investigated the status of the tractor operation device arrangement, developed convenience analysis tools for tractor operation devices, and performed bio-mechanical analysis on lower body including the waist in order to evaluate the tractor pedal operation convenience. All the processes were to support the ergonomic design of the tractor for convenience and safety of agricultural work, and provide basic data for the development of convenience evaluation system of the main operation device of agricultural tractors. 


\section{MATERIALS AND METHODS}

\section{TECHNOLOGY DEVELOPMENT}

When considering the current status of research at home and abroad, several agricultural machinery human engineering researches have conducted in the U.S. such as an ergonomic study on farmers' safety which provided ergonomic measures on the neck pain and back pain through musculoskeletal disorder risk assessment with EMG. Researches on the safety of agricultural machinery in Japan focused on the improvement of safety and amenity. To develop agricultural machinery which comfortably fit to Korean farmers including mature men, women, and seniors the machine designers should investigate the operators' body size, psychosomatic, and stamina. John Deere (Corp.) in United States conducted lots of simulation studies such as, evaluation of comfortable tractor driving with dynamic simulator, collaboration work simulation between combines and grain buggy, and tractor driving simulation. The John Deere (Corp.) also conducted an analysis on the work motion during agricultural work, and several studies on ergonomic cockpit batch design. Agricultural machinery manufacturers like Kubota and Yanmar in Japan designed agricultural machinery modified to Japanese farmers' body type by applying ergonomic skills such as universal design.

Studies on the comfortable levels of domestic agricultural machinery are at the early stages, and few studies have been carried out at the research institutes and universities. The rural development administration (RDA) have set a criteria for preventing farmers' musculoskeletal disorders and have used it for agricultural or extension worker education. Moreover, the RDA has conducted a project for the competitiveness of domestic tractors by establishing test criteria and making evaluations.

\section{TRACTOR OPERATING DEVICE RELATED STANDARD AND ARRANGEMENT INVESTIGATION}

For 40 models of tractors are sold in Korea, we have investigated the horizontal and vertical height of clutch pedal, brake pedal, accelerator pedal from the SIP. By using the design specifications that have been presented by each company as attachment of agricultural tractors type checking at the National Academy of Agricultural Sciences, driving operating device data were acquired, and the data were compared with KSB ISO 4253 and KSB ISO 6682 (driving operating device reach and comfortable range for earth-moving machine). ISO 4253 is the most basic and widely used international standard. Basic point of driver seat as reference point, ISO 4253 indicates the proper arrangement range of the pedal and handle, but has defined the position simply and do not have the standards concerning convenience and operating force. The disposed range of pedal following the ISO 4253 is determined to be excessively narrow, and it is hard to design the operation device with ease of drivers since the criteria does not provide information related to the operation force or convenience. The recently published ISO 15077 standard establishes a maximum operating force and maximum distance for all operating devices can be presented in the tractor driver seat. The standard is defined as follows: $100 \mathrm{~mm}$ minimum lever operating distance, maximum actuation force $80 \mathrm{~N}$, minimum pedal travel distance $30 \mathrm{~mm}$, and maximum pressure response $300 \mathrm{~N}$. Accordingly, it have been believed that tractor designer can design the operating force of the operating device with reference to the standard. However, this standard does not present the criteria for the driver convenience as well, and has difficulties in tractor design with a consideration for various operations. Besides, KSB ISO 6682 (Earthmoving machine - convenient and accessible operation area) shows the range of proper placement in a controllable range of operating device for earth-moving machineries such as excavator and loader. However, it is a standard that directly applied an ISO standard to Korea rather than those developed for domestic agriculture. As steerable region or convenient areas were defined based on the figure of westerners primarily domestic, it is unknown whether the standard is suitable for domestic driver, especially for the domestic agriculture.

\section{DEVELOPMENT OF COCKPIT MOCKUP AND OPERATING FORCE MEASURMENT DEVICE}

Tractor cockpit mockup which follows the standards ISO 4253 (operator's seating accommodation) and ISO 6682 (zone of comfort and reach for controls) is developed. The cockpit mockup has a height-adjustable driver seat, a clutch and brake pedal in the pedal part, and a steering wheel made with aluminum profiles in the steer-

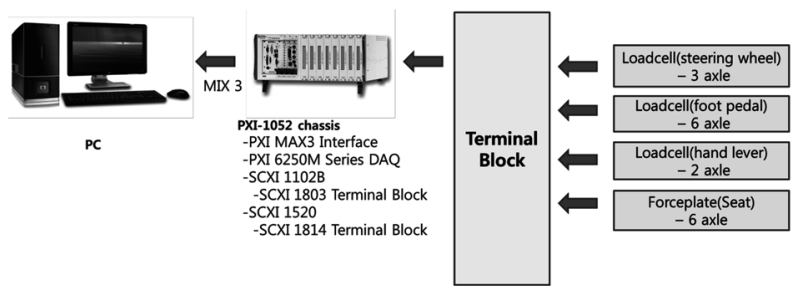

Fig. 1. Schematic of the operating force measurement system.

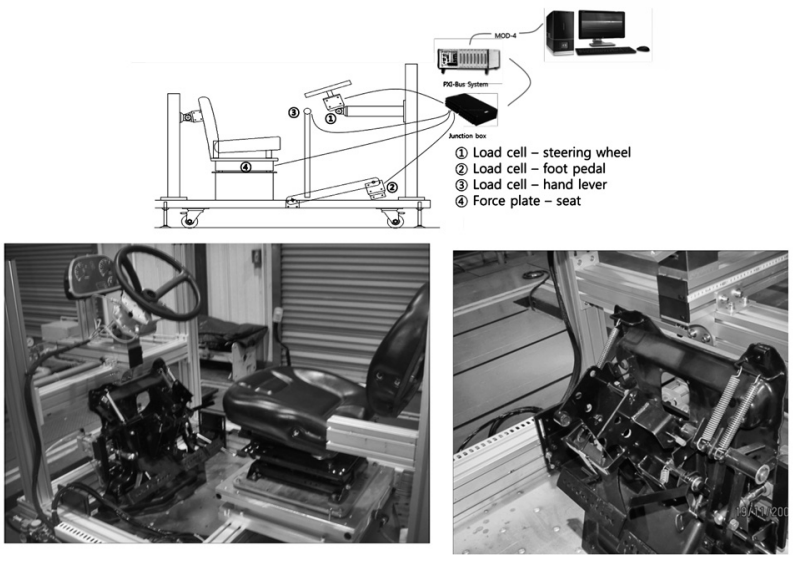

Fig. 2. Schematic of the mounted operating force measurement system on the cockpit mockup. 
ing part. Pneumatic manipulation load generation system is installed at hinged-type pedal, and the pedal part is designed to generate $0 \sim 800 \mathrm{~N}$. A force plate and load cells are equipped to measure the reaction force in the driver's seat and pedals, levers, and handle parts. And data collecting device is mounted for reaction force collection. Schematic diagram of the simulated cockpit and cockpit mockup, and force generate device developed to

Table 1. Human body measurements DB of the Korean males aged 40 59 (SizeKorea)

\begin{tabular}{|c|c|c|c|c|c|c|}
\hline No. & Items & Average & S.D. & 5 quintile & 50 quintile & 95 quintile \\
\hline 1 & Weight (lbs) & 69.63 & 9.35 & 54.7 & 69.2 & 85.45 \\
\hline 2 & Standing Height & 1672.4 & 56.27 & 1580.5 & 1670.5 & 1765 \\
\hline 3 & Right Shoulder Height & 1366.87 & 50.93 & 1283.5 & 1366.5 & 1452.5 \\
\hline 4 & Left Shoulder Height & 1366.87 & 50.93 & 1283.5 & 1366.5 & 1452.5 \\
\hline 5 & Right Armpit Height & 1239.12 & 48.59 & 1158 & 1237.5 & 1317.5 \\
\hline 6 & Left Armpit Height & 1239.12 & 48.59 & 1158 & 1237.5 & 1317.5 \\
\hline 7 & Waist Height & 1026.02 & 45.57 & 951.5 & 1024.5 & 1098.5 \\
\hline 8 & Seated Height & 907.21 & 32.17 & 854.5 & 906.5 & 960.5 \\
\hline 9 & Head Length & 176.08 & 22.05 & 146.5 & 169 & 206.5 \\
\hline 10 & Head Breadth & 153.63 & 19.31 & 128.5 & 145 & 182.5 \\
\hline 11 & Head to Chin Height & 212.67 & 29.97 & 174.5 & 202 & 255.5 \\
\hline 12 & Neck Circumference & 382.53 & 22.87 & 344.5 & 382.5 & 420.5 \\
\hline 13 & Shoulder Breadth & 389.88 & 23.04 & 349.5 & 390.5 & 424.5 \\
\hline 14 & Chest Depth & 218.74 & 17.67 & 189.5 & 218.5 & 248.5 \\
\hline 15 & Chest Breadth & 314.17 & 20.67 & 280.5 & 312.5 & 347.5 \\
\hline 16 & Waist Depth & 235.79 & 28.26 & 186.5 & 236.5 & 279.5 \\
\hline 17 & Waist Breadth & 289.44 & 21.87 & 251.5 & 289.5 & 325.5 \\
\hline 18 & Buttock Depth & 241.65 & 23.1 & 205.5 & 241.5 & 279.5 \\
\hline 19 & Hip Breadth Standing & 328.47 & 15.62 & 302.5 & 328.5 & 353.5 \\
\hline 20 & Right Shoulder to Elbow Length & 329.78 & 15.13 & 304.5 & 329.5 & 354.5 \\
\hline 21 & Left Shoulder to Elbow Length & 329.78 & 15.13 & 304.5 & 329.5 & 354.5 \\
\hline 22 & Right Forearm Hand Length & 261.67 & 12.91 & 238.5 & 261.5 & 283.5 \\
\hline 23 & Left Forearm Hand Length & 261.67 & 12.91 & 238.5 & 261.5 & 283.5 \\
\hline 24 & Right Biceps Circumference & 304.62 & 25.12 & 262.5 & 304.5 & 344.5 \\
\hline 25 & Left Biceps Circumference & 304.62 & 25.12 & 262.5 & 304.5 & 344.5 \\
\hline 26 & Right Elbow Circumference & 289.58 & 23.4 & 251.5 & 289.5 & 329 \\
\hline 27 & Left Elbow Circumference & 289.58 & 23.4 & 251.5 & 289.5 & 329 \\
\hline 28 & Right Forearm Circumference & & & & & \\
\hline 29 & Left Forearm Circumference & & & & & \\
\hline 30 & Right Wrist Circumference & 170.36 & 8.8 & 155.5 & 169.5 & 183.5 \\
\hline 31 & Left Wrist Circumference & 170.36 & 8.8 & 155.5 & 169.5 & 183.5 \\
\hline 32 & Right Knee Height Seated & 497.31 & 22.87 & 460.5 & 496.5 & 536.5 \\
\hline 33 & Left Knee Height Seated & 497.31 & 22.87 & 460.5 & 496.5 & 536.5 \\
\hline 34 & Right Thigh Circumference & 494.3 & 37.65 & 431.5 & 494.5 & 552.5 \\
\hline 35 & Left Thigh Circumference & 494.3 & 37.65 & 431.5 & 494.5 & 552.5 \\
\hline 36 & Right Upper Leg Circumference & 544.18 & 42.79 & 471 & 545.5 & 611.5 \\
\hline 37 & Left Upper Leg Circumference & 544.18 & 42.79 & 471 & 545.5 & 611.5 \\
\hline 38 & Right Knee Circumference & 365.55 & 19.86 & 33 & 365.5 & 399.5 \\
\hline 39 & Left Knee Circumference & 365.55 & 19.86 & 33 & 365.5 & 399.5 \\
\hline 40 & Right Calf Circumference & 364.78 & 26.81 & 320.5 & 363.5 & 408.5 \\
\hline 41 & Left Calf Circumference & 364.78 & 26.81 & 320.5 & 363.5 & 408.5 \\
\hline 42 & Right Ankle Circumference & 255.24 & 14.01 & 233.5 & 255 & 278 \\
\hline 43 & Left Ankle Circumference & 255.24 & 14.01 & 233.5 & 255 & 278 \\
\hline 44 & Right Ankle Height Outside & 67.17 & 5.01 & 59.5 & 66.5 & 75.5 \\
\hline 45 & Left Ankle Height Outside & 67.17 & 5.01 & 59.5 & 66.5 & 75.5 \\
\hline 46 & Right Foot Breadth & 100.58 & 4.68 & 92.5 & 99.5 & 107.5 \\
\hline 47 & Left Foot Breadth & 100.58 & 4.68 & 92.5 & 99.5 & 107.5 \\
\hline 48 & Right Foot Length & 250.51 & 10.37 & 233.5 & 249.5 & 267.5 \\
\hline 49 & Left Foot Length & 250.51 & 10.37 & 233.5 & 249.5 & 267.5 \\
\hline
\end{tabular}


generate pedal reaction force during the operation are shown in Fig. 2. Also, an operating force measurement system that can measure stamping force during pedal stamp, operating force during lever operation, and force of the steering wheel is developed. The developed operating force measurement system is composed with force plate which measures reaction force at the cockpit, 6 -axis load cell for the stamping force measurement in the pedals, 3-axis load cell to measure the forces exerted on the steering wheel, lever operating force sensor with built-in 2-axis load cell for the lever operating force, and NI's PXI-BUS system which receives signals from the sensors, amplifies, and sends data to a computer. Operating force measurement system needs signal conversion from the sensor into operating force and an additional operation measurement program to store and edit data. Fig. 1 is the schematic of the measurement system. In addition, the schematic of the mounted operating force measurement system on the cockpit mockup is shown in Fig. 2.

\section{MOTION ANALYSIS SYSTEM FOR TRACTOR PEDAL CONVENIENCE ANALYSIS}

Fig. 3 shows an image measurement system for measuring the driver's behavior while operating. For the motion analysis, eight Hawk-class near-infrared imaging sensors are installed and the motions of driver's body with marker recognition program(Cortex, Motion analysis) are recorded by tracking markers attached to the driver body in three-dimension. The default position of the seat, pedals, lever, and handle in cockpit simulator were adjusted by a subject following the operation system of medium-sized tractor from a domestic company A (Corp.). The subjects were male between 40-59 years old. Test was started in a default setting of the driver's seat and pedal which used in the computer modeling. A motion with $100 \mathrm{~N}$ of force at pedaling and the same motions were replicated with adjusting the position of the pedals and seat. The seat points were set as three positions: reference point, $7.5 \mathrm{~cm}$ anterior from the reference point, and $7.5 \mathrm{~cm}$ posterior from the reference point. The pedal points were also set as three positions: reference point, $5 \mathrm{~cm}$ left from the reference point, and $5 \mathrm{~cm}$ right from the reference point. Each position in the

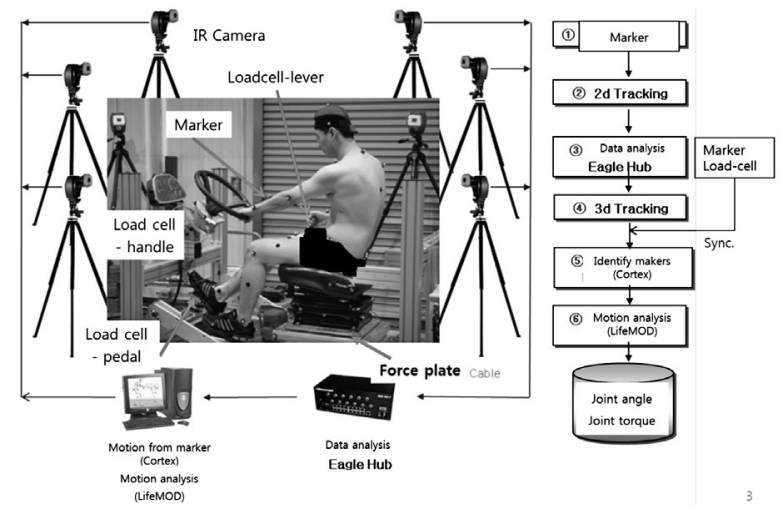

Fig. 3. Image measurement systems. seat and pedals of motion data was entered into the program LifeMOD, and joint angles and joint loads were calculated. Fig. 4 shows a process calculating the load and joint angles by using the LifeMOD. During the process human body model was developed using the average body size of Korean male aged in 40 to 49 years, which was investigated at the Technical Standard Institute. According to the paper reported in Journal of the Korean Society of Clothing and Textiles, human body measurements of the Korean standard male and Korean male farmers have no differences (Journal of the Korean Society of Clothing and Textiles, 2007 Fall). Following the reference, Korean male size measurement, 40 69 olds male size was assumed to be as same as that of the male population of the rice cropping farmers. Under the assumption "Body type factors are same between the Korean males and tractor operators aged from 40 to 60." human body measurements of the Korean males were investigated from the human body measurement data-

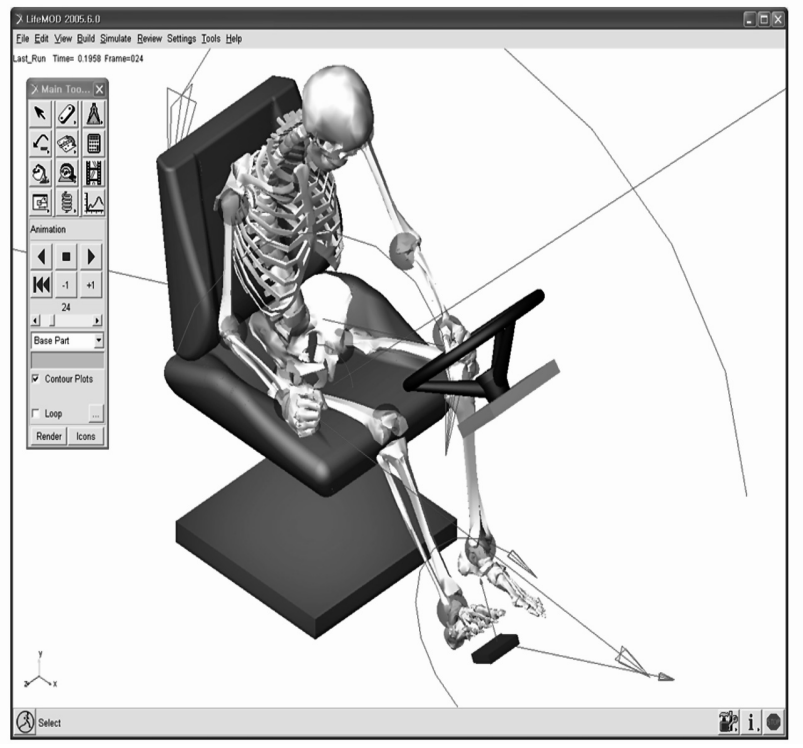

Fig. 4. LifeMOD, Joint angle and joint load calculation.

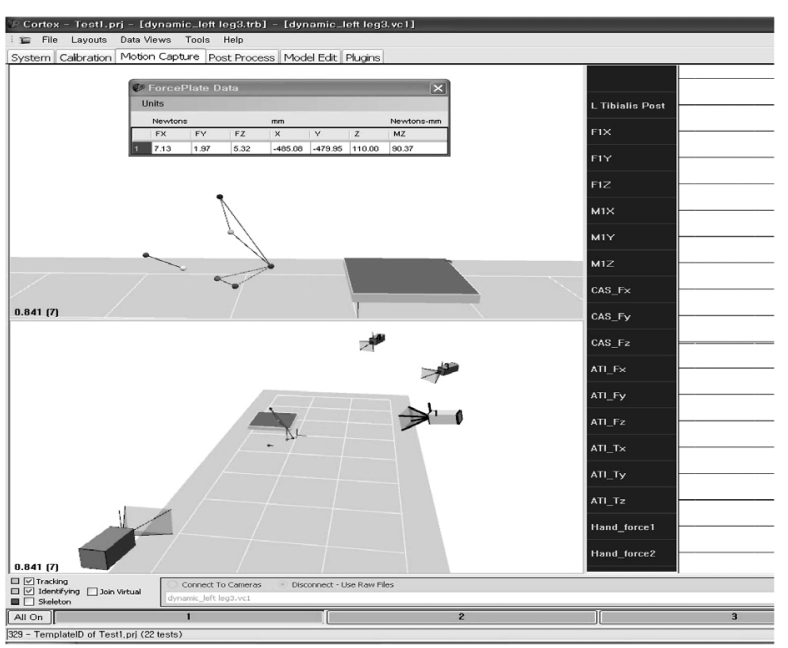

Fig. 5. Image measurement data during pedal stamping. 
base provided by the 'Size Korea'. Table 1 shows average, standard deviation, 5 quintile (small size), 50 quintile (medium size), 95 quintile (big size) for each items.

With the developed motion analysis system, the driving positions and postures are measured in real time through the image measurement system, and the reaction force is measured by the measuring device simultaneously. And then the motions are analyzed by motion analysis program. Fig. 5 shows a measurement result of the motion in the driver's leg during a pedaling with the developed image measurement system.
TRACTOR OPERATION POSTURES AND EVALUATION CRITERIA

According to Ryu et al. (2004), driving posture influences the convenience of the drivers. Therefore, for an evaluation on the ease of operating device, extracted the range of motion (angle) in joints according to each tractor operating motions was evaluated following the criteria shown in Fig. 6.

Table 2 below shows criteria on the joint range of motion on the lever and pedal in Fig. 6. If workers perform works within the range of appropriate criteria, they

Table 2. Evaluation criteria for the range of motion in joint

\begin{tabular}{|c|c|c|c|c|}
\hline Angle part & Plane & Direction & Posture & Range of the ease \\
\hline \multirow{6}{*}{ Head } & \multirow{2}{*}{ Sagittal } & +30 & front bow & +30 \\
\hline & & -30 & backward & -30 \\
\hline & \multirow{2}{*}{ Transverse } & + & left rotation & model standard \\
\hline & & - & right rotation & model standard \\
\hline & \multirow{2}{*}{ Frontal } & +20 & right bow & +20 \\
\hline & & -20 & left bow & -20 \\
\hline \multirow{6}{*}{ R/L Shoulder } & \multirow{2}{*}{ Sagittal } & +15 & backward stretch & +15 \\
\hline & & -35 & front stretch & -35 \\
\hline & \multirow{2}{*}{ Transverse } & + & left rotation & model standard \\
\hline & & - & right rotation & model standard \\
\hline & \multirow{2}{*}{ Frontal } & +0 & left stretch & +0 \\
\hline & & -30 & right stretch & -30 \\
\hline \multirow{6}{*}{ R/L Elbow } & \multirow{2}{*}{ Sagittal } & + & backward stretch & model standard \\
\hline & & $-40 \sim 80$ & front stretch & $-40 \sim 80$ \\
\hline & \multirow{2}{*}{ Transverse } & + & left rotation & model standard \\
\hline & & - & right rotation & model standard \\
\hline & \multirow{2}{*}{ Frontal } & + & left stretch & model standard \\
\hline & & - & right stretch & model standard \\
\hline \multirow{6}{*}{ R/L Wrist } & \multirow{2}{*}{ Sagittal } & +45 & backward stretch & +45 \\
\hline & & -25 & front stretch & -25 \\
\hline & \multirow{2}{*}{ Transverse } & +70 (Left:8) & left rotation & +70 (Left:8) \\
\hline & & -8 (Left:70) & right rotation & -8 (Left:70) \\
\hline & \multirow{2}{*}{ Frontal } & + & left stretch & model standard \\
\hline & & - & right stretch & model standard \\
\hline \multirow{6}{*}{ R/L Hip } & \multirow{2}{*}{ Sagittal } & + & lower body backward stretch & model standard \\
\hline & & $-60 \sim-95$ & lower body front stretch & $-60 \sim-95$ \\
\hline & \multirow{2}{*}{ Transverse } & + & left rotation & model standard \\
\hline & & - & right rotation & model standard \\
\hline & \multirow{2}{*}{ Frontal } & + & left stretch & model standard \\
\hline & & - & right stretch & model standard \\
\hline \multirow{6}{*}{ R/L Knee } & \multirow{2}{*}{ Sagittal } & $+45 \sim+85$ & backward stretch & $+45 \sim+85$ \\
\hline & & - & front stretch & model standard \\
\hline & \multirow{2}{*}{ Transverse } & + & left rotation & model standard \\
\hline & & - & right rotation & model standard \\
\hline & \multirow{2}{*}{ Frontal } & + & left stretch & model standard \\
\hline & & - & right stretch & model standard \\
\hline \multirow{6}{*}{ R/L Ankle } & Sagittal & $+0 \sim+20$ & ankle plantar flexion & $+0 \sim+20$ \\
\hline & & - & ankle dorsiflexion & model standard \\
\hline & Transverse & +15 & left rotation & +15 \\
\hline & mansverse & -15 & right rotation & -15 \\
\hline & Frontal & + & right rotation & model standard \\
\hline & Flomilal & - & left rotation & model standard \\
\hline
\end{tabular}




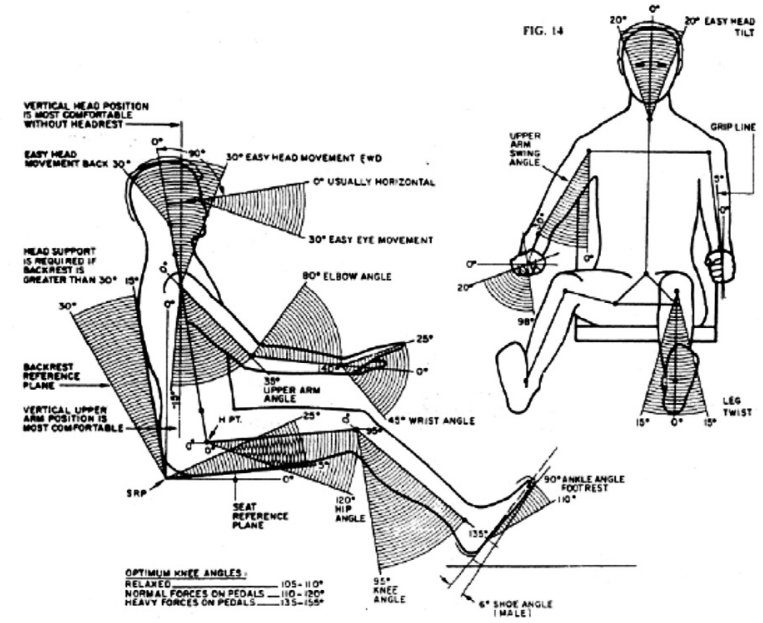

Fig. 6. Joint range of motion for ease operation (2004. Ryu Kwan Hee. Munundang. Tractor engineering).

do not feel significant discomfort during the tractor operation.

\section{RESULTS AND DISCUSSION}

\section{TRACTOR OPERATING DEVICE ARRANGEMENT INVESTIGATION RESULT}

Fig. 7 shows the displacement of the tractor drivingoperation devices. According to the investigation based on ISO $6682,30 \%$ of the range in the lever, $80 \%$ in the clutch pedal, $78 \%$ in the handle, $73 \%$ in the brake pedal, and $92 \%$ in the accelerator were determined to be out ranged from the comfortable range. The proper displacement range ruled by ISO 4253 has much smaller area than that of the ISO6682; it is found that the range of clutch, break, and accelerator in most of the tractor models investigated were out-ranged. Therefore, driving operation device of the tractors available in Korea are determined to be taking into account the convenience of the driver insufficiently.
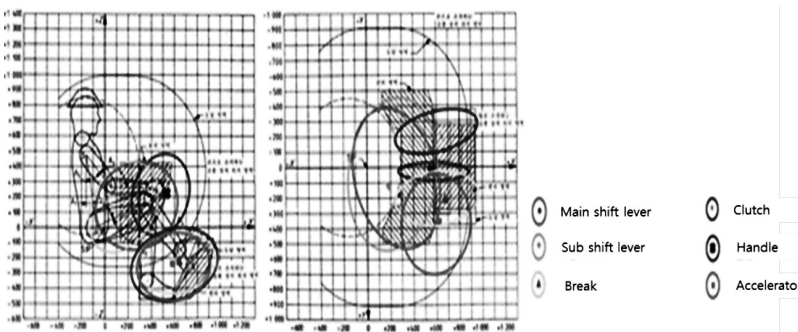

Fig. 7. Investigated range of operation devices.

\section{HUMAN MODEL VERIFICATION}

For a bio-mechanical analysis of the tractor worker with human model, kinematic factors and kinetic factors were measured, and simulated using the analysis program 'ADAMS LifeMOD'. The process is same as follows: first, acquired data of the motions by using the 6 infrared cameras, gait and lifting, which will be performed by human simulation model and used for verification of the model. Second, utilizing the data, built a human body model in ADAMS LifeMOD, and set the whole body movements. The parameters examined in gait motion for the model verification were ground reaction force, center of gravity, joint angle, and joint torque. The load at the waist compared with the value joint force floor is measured for model validation from walking, is presented in the bibliography at the operating lift. The first step in creating a human body model is human body segments composition. Nineteen of body segments were built using the anthropometric database. The segments required to build a human model are as follows: head, neck, upper torso, mid torso, lower torso, left and right shoulders, left and right upper arms, left and right forearms, left and right hands, left and right upper legs, left and right lower legs, and left and right foot. Human body is simplified to segments of the body of this 19 pieces, and it is possible to have detailed analysis in a specific region by dividing the segments into several multiple segments. The foot is consisted of multiple bones, and they are connected with tendons or ligaments. In this study, foot was set as one segment, and contact between the foot and the ground was modeled by setting the six contact-ellipsoids. In this study, we take advantage of the Korean integrated research business SizeKOREA DB, one of the human body information DB widely used in kinetic analysis of heavy equipment operator and vehicle.

The study of simulation using the ADAMS LifeMOD need a human body model, and need verification of the model usefulness by implementing motions. The verifying method for the model should be selected with the characteristic of work to be implemented beforehand. The main motions in the tractor work can be classified as follows: motion of pulling the lever and pedaling. Since the verification of the whole body movement is necessary, task of lifting and walking, representative and general movement of human body, were targeted for the verification.

In case of the center of gravity, all three traveling direction $(\mathrm{X})$, lateral direction $(\mathrm{Y})$ and vertical direction (Z) had values less than $10 \%$, and were included within $15 \%$ you are of the appropriate standard of analysis. The absolute difference showed a value smaller than the value presented in the previous study (Pen et al., 2004), and correlation was higher with correlation coefficient higher than 0.7 (Jon-Deyon, Basic social statistics).

When the kinematic data are examined, relative position differences of the ankle, knee, and hip joint had values of less than $10 \%$, and all were within $15 \%$, a moderate standard for bio-mechanical analysis. The absolute differences were less than 5 degrees on average, and showed 0.9 or more of high correlation coefficient.

When check out the reaction force occurred during gait, both left and right had a value below 10\% in case of the relative position difference value, and it was suitable standard for bio-mechanical analysis, 15\% (Wojtyra, 1999). The absolute position, all the values showed under than the value shown in the literature (Gilchrist, 1997). The correlation, except for the left and right side 
Table 3. Verification result on Center of gravity

\begin{tabular}{cccccccccc}
\hline & \multicolumn{3}{c}{ Absolute Difference } & \multicolumn{3}{c}{ Relative Difference (\%) } & \multicolumn{3}{c}{ Correlation (r) } \\
\hline & $\mathrm{X}$ & $\mathrm{Y}$ & $\mathrm{Z}$ & $\mathrm{X}$ & $\mathrm{Y}$ & $\mathrm{Z}$ & $\mathrm{X}$ & $\mathrm{Y}$ & $\mathrm{Z}$ \\
\hline Average & -7.0635 & -0.1834 & -0.8771 & 3.1662 & 0.0379 & 0.1949 & 0.9990 & 0.7830 & 0.7392 \\
SD & 7.9434 & 6.2931 & 5.4983 & 2.5934 & 0.6611 & 2.4391 & 0.0017 & 0.1327 & 0.1722 \\
\hline
\end{tabular}

Table 4. Verification result on kinematic data of each joint

\begin{tabular}{|c|c|c|c|c|c|c|c|c|c|}
\hline \multirow[t]{2}{*}{ Left } & \multicolumn{3}{|c|}{ Absolute Difference } & \multicolumn{3}{|c|}{ Relative Difference (\%) } & \multicolumn{3}{|c|}{ Correlation (r) } \\
\hline & Ankle & Knee & Hip & Ankle & Knee & Hip & Ankle & Knee & Hip \\
\hline Average & 1.1655 & 0.0142 & 0.6236 & -9.1692 & 0.6986 & -1.9676 & 0.9738 & 0.9955 & 0.9917 \\
\hline $\mathrm{SD}$ & 0.9505 & 1.3490 & 1.2673 & 3.9277 & 10.0401 & 5.3587 & 0.0245 & 0.0014 & 0.0069 \\
\hline \multirow[t]{2}{*}{ Right } & \multicolumn{3}{|c|}{ Absolute Difference } & \multicolumn{3}{|c|}{ Relative Difference (\%) } & \multicolumn{3}{|c|}{ Correlation (r) } \\
\hline & Ankle & Knee & Hip & Ankle & Knee & Hip & Ankle & Knee & Hip \\
\hline Average & 0.0339 & -0.5427 & -0.5551 & 1.2844 & 5.4749 & -1.5234 & 0.9665 & 0.9946 & 0.9947 \\
\hline SD & 0.8405 & 3.1791 & 1.7657 & 9.4505 & 11.5592 & 5.0780 & 0.0287 & 0.0014 & 0.0020 \\
\hline
\end{tabular}

Table 5. Verification result on ground reaction force during a gait simulation

\begin{tabular}{crrrrrrr}
\hline & \multicolumn{3}{c}{ Left Foot } & \multicolumn{3}{c}{ Right Foot } \\
\cline { 2 - 6 } Contents & $\mathrm{X}$ & $\mathrm{Y}$ & $\mathrm{Z}$ & $\mathrm{X}$ & $\mathrm{Y}$ & $\mathrm{Z}$ \\
\hline Relative Position Differences (\%) & -2.49 & - & -4.22 & 14.53 & - & -1.42 \\
Absolute Position Differences (N) & -6.62 & -0.68 & 8.71 & -0.97 & 2.39 & 10.74 \\
Pearson's Correlation Coefficients & 0.94 & 0.62 & 0.94 & 0.94 & 0.94 & 0.94 \\
\hline
\end{tabular}

X : Forward-Backward, Y : Left-Right, Z : Upward-Downward

horizontal force, correlation of the all forces were very high. (Jon-Deyon, Basic social statistics)

During the lifting experiment, the task varies according to the distance and height between weight, and need to be same as much as possible with the experiment performed at previous studies. The maximum and average torque values of the lumbar portion were determined, and compared with that of the previous study (Kingma et al., 1998). The comparison result is shown in Fig. 8.

A computer human body model was developed by LifeMOD program. The model was verified by comparing the load generated at the lumbar during lifting task and the lumbar load from the previous study (Kingma et al, 1998), and had no great difference. Therefore, the verification of the computer human model developed through LifeMOD was determined to have no problem.

Using the driver seat mockup, the normal force from

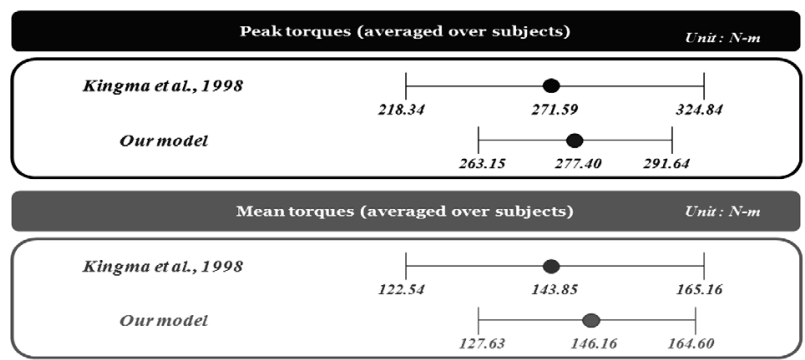

Fig. 8. Comparison of the load at lumber region with the previous study. the computer tractor simulation (Fig. 11) and the force from the load cell were compared. Fig. 9 shows the human body model stepping the brake pedal. Fig. 10 graphically representation the reaction force values obtained by the load cell when press the actual pedal (red line) and results obtained using the human body model (blue line). The results obtained in the human body model was $102.45( \pm 0.87) \mathrm{N}$ in average, and matched $97.6 \%$ with the actual reaction force from load cell $100 \mathrm{~N}$.

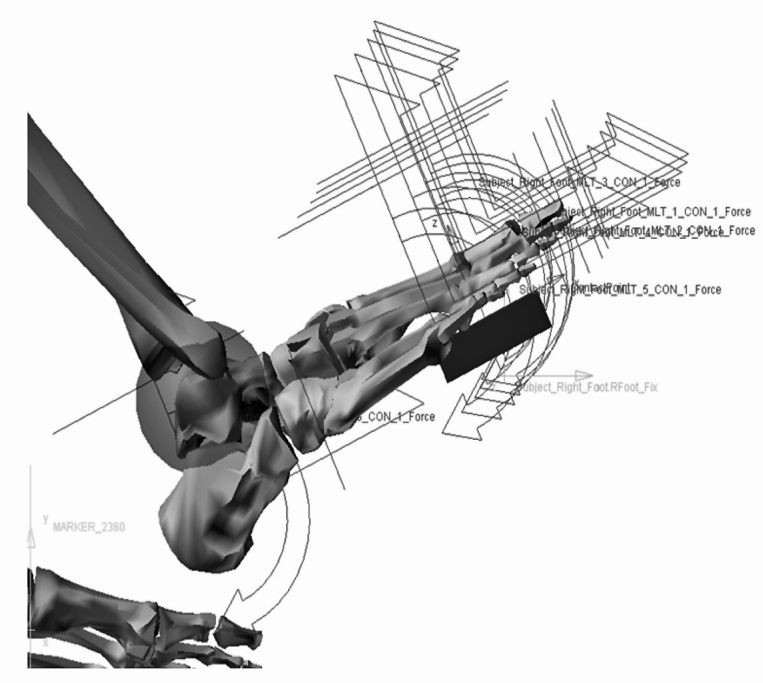

Fig. 9. Clutch pedal modeling. 


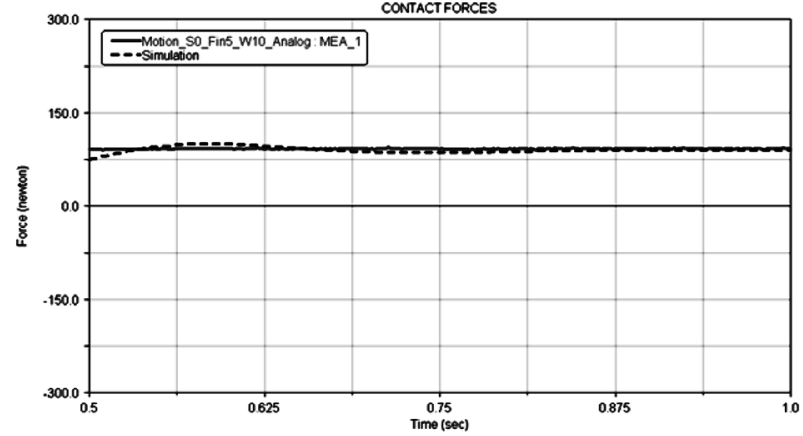

Fig. 10. Comparison between the real and simulation value.

\section{CONVENIENCE ANALYSIS RESULT USING THE JOINT ANGLE}

Fig. 11 and 12 shows a scene from pedal and lever operating experiment, and drawn simulation result, respectively.

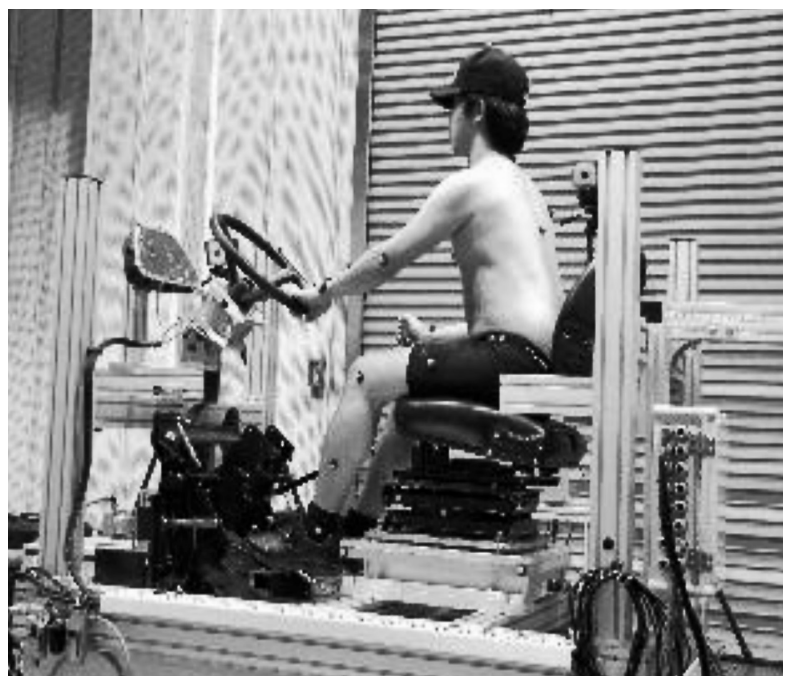

Fig. 11. Experiment picture - pedal andlever operation.
Evaluation results on the ease of use with the measured joint angles are listed in Table 6 .

According to the result, 1, 4, and 6 postures show to be uncomfortable on the sagittal plane, and the cause of this discomfort may be from the position of the sight on pedal while working a pedal. On the sagittal plane of the right knee, discomfort is shown during 7,8 , and 9 postures, and the cause of this may be the far position of pedal. Also, both left and right hip joint on the sagittal plane shows discomfort due to the uncomfortable seat on the cockpit.

\section{CONVENIENCE ANALYSIS RESULT USING THE WAIST LOAD}

The shear force and compressive force take at the waist shown in Table 7. Also, when the maximum values shown in Table 7 are displayed as a graph, they are the same as in Fig. 15.

Fig. 15 shows maximum values of the shear force and compressive force take at the waist with $100 \mathrm{~N}$ of break pedaling. All the compressive-strength (COMP) satisfies

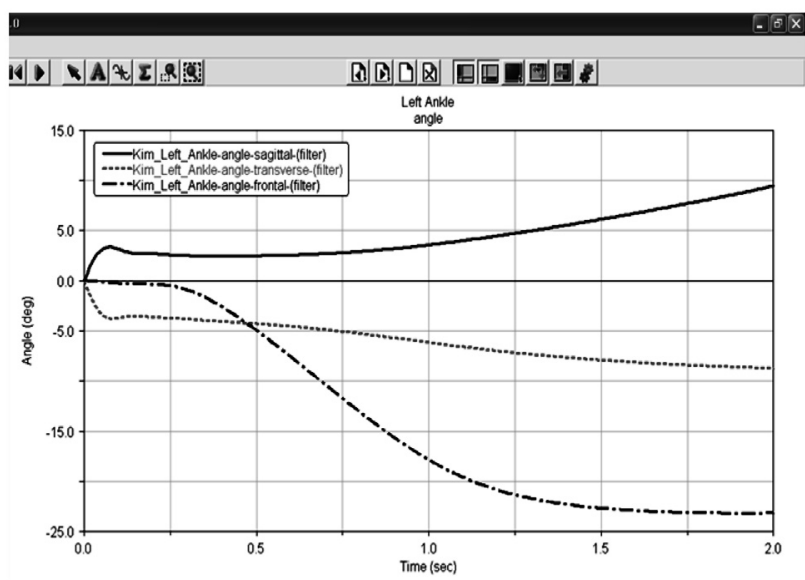

Fig. 12. Left ankle angle at the reference position with middle size tractor.

Table 6. The evaluation result on the ease based on the angles

\begin{tabular}{|c|c|c|c|c|c|c|c|c|c|c|}
\hline & Plane & 1 & 2 & 3 & 4 & 5 & 6 & 7 & 8 & 9 \\
\hline & S & discomfort & comfort & comfort & discomfort & comfort & discomfort & comfort & comfort & comfort \\
\hline Head & $\begin{array}{l}\mathrm{T} \\
\mathrm{F}\end{array}$ & $\begin{array}{c}- \\
\text { comfort }\end{array}$ & $\begin{array}{c}- \\
\text { comfort }\end{array}$ & $\begin{array}{c}- \\
\text { comfort }\end{array}$ & $\begin{array}{c}- \\
\text { comfort }\end{array}$ & $\begin{array}{c}- \\
\text { comfort }\end{array}$ & $\begin{array}{c}- \\
\text { comfort }\end{array}$ & $\begin{array}{c}- \\
\text { comfort }\end{array}$ & $\begin{array}{c}- \\
\text { comfort }\end{array}$ & $\begin{array}{c}- \\
\text { comfort }\end{array}$ \\
\hline R. Hip & S & discomfort & discomfort & discomfort & discomfort & discomfort & discomfort & discomfort & discomfort & discomfort \\
\hline L. Hip & S & discomfort & discomfort & discomfort & discomfort & discomfort & discomfort & discomfort & discomfort & discomfort \\
\hline R. Knee & S & comfort & comfort & comfort & comfort & comfort & comfort & discomfort & discomfort & discomfort \\
\hline R. Ankle & $\mathrm{S}$ & comfort & comfort & comfort & comfort & comfort & comfort & comfort & comfort & comfort \\
\hline
\end{tabular}

Author) 1: Default position of the cockpit and pedal

2: Default position of the cockpit, Pedal $50 \mathrm{~mm}$ inside

3: Default position of the cockpit, Pedal $50 \mathrm{~mm}$ outside

4: Cockpit $75 \mathrm{~mm}$ forward, Pedal default

5. Cockpit $75 \mathrm{~mm}$ forward, Pedal $50 \mathrm{~mm}$ inside

6. Cockpit $75 \mathrm{~mm}$ forward, Pedal $50 \mathrm{~mm}$ outside

7: Cockpit $75 \mathrm{~mm}$ backward, Pedal default

8: Cockpit $75 \mathrm{~mm}$ backward, Pedal $50 \mathrm{~mm}$ inside

9: Cockpit $75 \mathrm{~mm}$ backward, Pedal $50 \mathrm{~mm}$ outside 
the NIOSH criteria $(3,400 \mathrm{~N}$, Waters et al., 1993). When the result is analyzed, relatively large load appears in the default cockpit location, and the COMP is reduced as the location adjusted to the forward or backward. Also, the biggest load $(3,343 \mathrm{~N})$ is appeared as the pedal locates to the outwards from the default location. The anteriorposterior shear force (ANT_SH) shows significantly higher value at default cockpit location and left/right range of the pedal position than other postures. It exceeds maximum permissible standard $(1,000 \mathrm{~N})$ and

Table 7. Shear force and compressive force take at the waist (unit:N)

\begin{tabular}{|c|c|c|c|c|c|c|c|c|c|}
\hline \multirow{2}{*}{ Class } & \multicolumn{3}{|c|}{ MAX } & \multicolumn{3}{|c|}{ AVG } & \multicolumn{3}{|c|}{ MIN } \\
\hline & ANT_SH & COMP & LAT_SH & ANT_SH & COMP & LAT_SH & ANT_SH & COMP & LAT_SH \\
\hline 1 & 384.09 & $2,561.53$ & 406.55 & -97.019 & 1882.632 & 47.30346 & -285.954 & 8.76997 & -24.4988 \\
\hline 2 & 1380.685 & 2954.663 & 12.17424 & 979.4734 & 2387.539 & -16.6699 & -43.5531 & 2.93843 & -81.6843 \\
\hline 3 & 991.6504 & 3343.159 & 658.1115 & 652.5797 & 2624.722 & 457.8717 & -319.192 & 7.48619 & 11.24216 \\
\hline 4 & 364.9477 & 617.0101 & 203.0799 & 330.0011 & 576.165 & 149.689 & -47.4045 & 7.15427 & 8.915806 \\
\hline 5 & 315.1699 & 633.339 & 162.696 & 276.7687 & 545.1998 & 143.4227 & -37.6722 & 9.30553 & 11.37378 \\
\hline 6 & 332.9775 & 570.4118 & 199.7597 & 305.5871 & 528.4459 & 170.7862 & -72.1741 & 1.12023 & -5.47217 \\
\hline 7 & 661.1428 & 888.3096 & 455.7758 & 612.7965 & 823.9175 & 338.7367 & -66.7587 & 4.85235 & 2.150117 \\
\hline 8 & 405.3107 & 772.9148 & 141.0301 & 330.043 & 585.0147 & 78.65405 & -37.01 & -2.33 & 5.06 \\
\hline 9 & 262.1468 & 437.9146 & 11.01333 & 234.3021 & 402.1396 & -42.636 & -73.441 & 4.18864 & -57.7197 \\
\hline
\end{tabular}

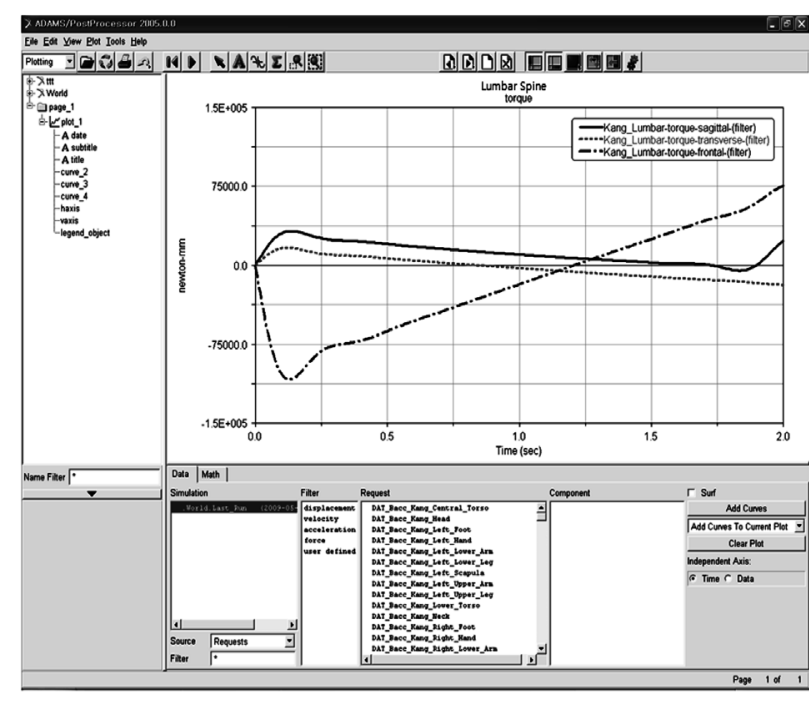

Fig. 13. Lumber spine torque at the reference position with small size tractor.

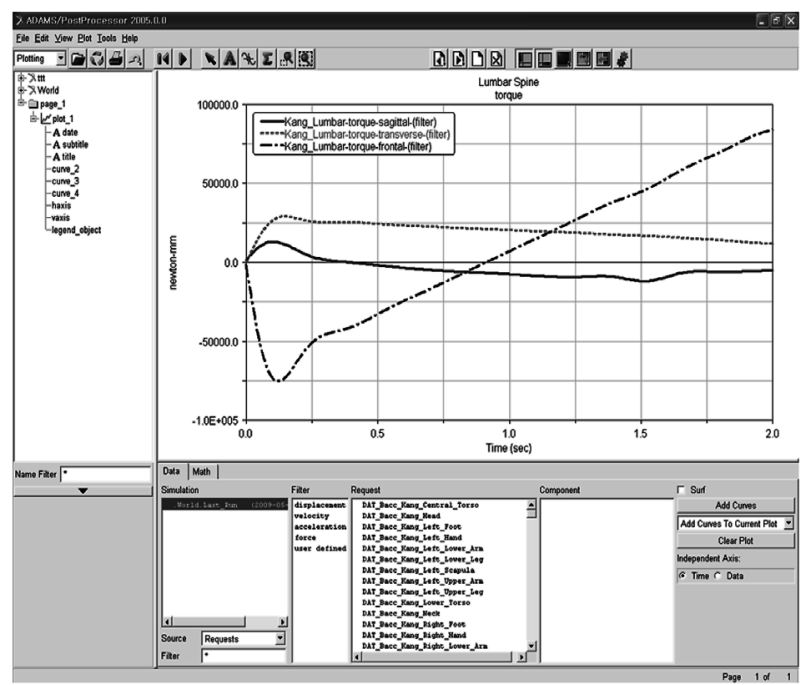

Fig. 14. Lumber spine torque at the 3-point posterior position with small size tractor.

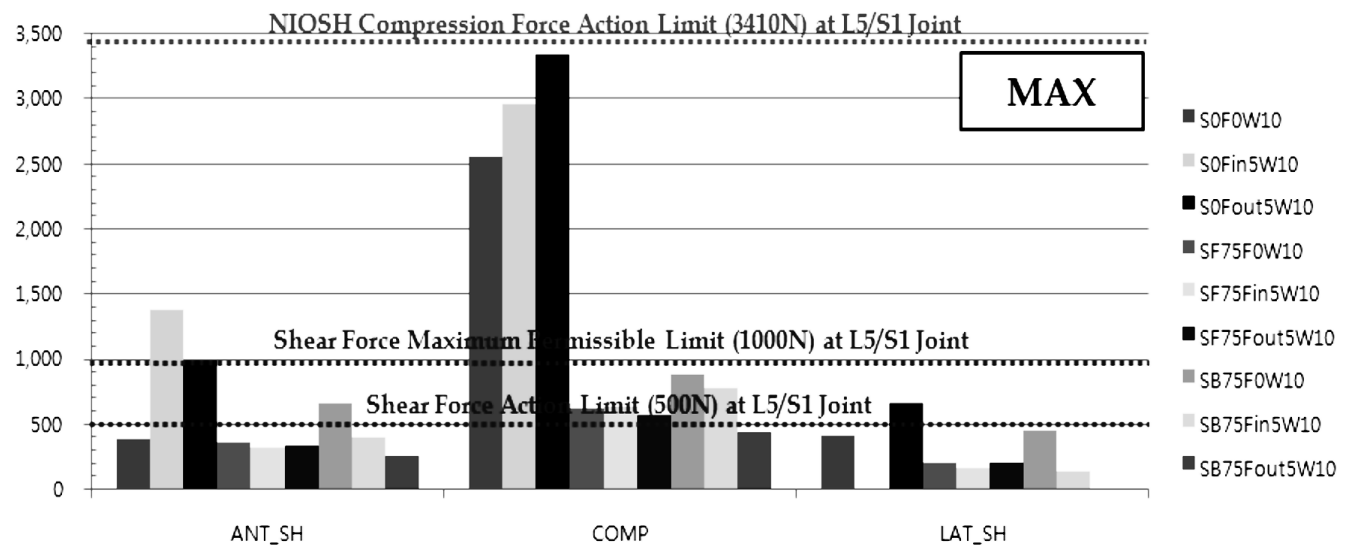

Fig. 15. Maximum values of the shear force and compressive force take at the waist. 
permissible operating standard $(500 \mathrm{~N})$ on NIOSH standards (Waters et al., 1993). Additionally, decreasing shear force is measured as the seat location adjusted to the front and rear. To conclude, the default cockpit location is burdening to the average 50 years of middle aged men, and the burden can be reduced by adjusting the cockpit location. The results of this study cannot be applied to the whole domestic tractors' cockpit, because the range of proper placement and navigating method are the only for the simulation.

\section{CONCLUSIONS}

The purpose of this study is the comfort evaluation technique development for tractor design. The thchniques can be utilized in operation device design by considering the body size of Korean farmers. In this study, only one result from the one domestic company A's middle-size tractor is recorded for the proper range of operation device placement, nevertheless manufacturers and designers should utilize the testing methods for operating device design by following the same sequence carried out from this study. The results from this study can be summarized as follows:

A. According to the investigation based, 30\% of the range in the lever, $80 \%$ in the clutch pedal, $78 \%$ in the handle, $73 \%$ in the brake pedal, and $92 \%$ in the accelerator were determined to be out ranged from the comfortable range based on ISO 6682, We could found that tractors without considering the convenience of the driver, when designing the driving operation device of tractors, is supplied.

B. Have developed a tractor driver seat simulator which can accommodate a range of displacement of the driving operation device according to the ISO 6682 and ISO 4253.

C. Have configured a video measurement system for measuring the motion of the driver during driving and operation. The movable angle and load to the joint were estimated by the image sensor measurement data, when the driver sitting in the driver's seat simulator stepped on simulated pedal, and LifeMOD program.

D. The convenience of the brake pedal operation was evaluated. As the result of evaluation, discomfort at left and right hips was observed in the entire positions and postures; discomfort at the right knee was observed when move the seat $7.5 \mathrm{~cm}$ backwards; discomfort at the left knee was observed when move the seat $7.5 \mathrm{~cm}$ forward.

E. The load evaluation result at waist satisfied the NIOSH criteria, but the load was relatively large when the seat was at the default location, and the compression force reduced when adjusts the seat back and forth. Furthermore, the largest load was observed $(3,343 N)$ when moving the pedal outward from the default location. Higher anterior and posterior shear force than other motions was observed at the left and right pedal location, and the default location; especially, allowable operating reference value and the maximum permissible reference value exceeding NIOSH criteria in the default location was observed. When adjust the seat back and forth, the shear force was reduced.

F. The entire process performed in the present study works as a method to perform a convenience evaluation for diverse conditions at the design stage or to evaluate convenience on a developed agricultural tractor. The tractor manufacturers can make an evaluation on the range of operation device placements and can determine optimal location of operation devices and operating force on a targeted developing model by utilizing the ease evaluation system and method developed in this study. Also, it can be used for the quality inspection by conducting individual ease evaluation on the tractors in prototype development phase. Besides, the evaluation method and system from this study can also be utilized at the operating difficulty test that conducted by tractor testing station. To be specific, the ease of use evaluation based on arranging position and operating force, which is considered to be the most significant inconvenience operating device among the agricultural tractors for investigation, can be carried out by using the evaluation system from this study.

\section{REFERENCES}

Korean Agency for Technology and Standards. KSB ISO 6682. 1999

Park Se Jin. Development of Seat to Reduce the Vibration Discomfort of Agriculture Tractor. 2002

Statistics Korea. 2005 Agricultural Investigation. 2006

EC Directive 78/764/EEC. 1978. Driving seat

ISO. ISO-4253, ISO-15077 Standard. 2002

Kingma, I., M. P. de Looze, J. H. van Dieën, H. M. Toussaint, M. A. Adams and C. T. Baten. 1998. When is a lifting movement too asymmetric to identify low-back loading by $2-\mathrm{D}$ analysis? Ergonomics 41(10): 1453-1461

Liang Chen, Rana Balci, Alicia Vertiz. 2003. 2003 SAE world Congress. Safety Belt Fit, Comfort, and Contact Pressure Based on Upper Anchorage Location and Seat Back Angle: 2

NIAE(National institute of agricultural machinery). 2007. Work Manual

Pan, C. S., K. M. Miller, C. Sharon and John A. Wu. 2004. Evaluation of a Computer-Simulation Model for Human Ambulation on Stilts. Journal of Mechanics in Medicine and Biology 4: 283-303

Park, Se Jin. 2002. Development of seat to reduce the vibration discomfort of agricultural tractor. KRISS/IR-2002-057

R.H. Rautiainen. S. J. Reynolds. 2002. Mortality and Morbidity in Agriculture in the United States. Journal of Agricultural Safety and Health 8(3): 259-276

Ryu, Kwan Hee. 2004. Tractor Engineering Principles. Korean Society of Agricultural Engineering. pp. 429-431

Seoung Yeup Shin. 2006. Research on the surveying of accidents caused by agricultural machinery. NIAE(National institute of agricultural machinery) research report: 109-120

Tomita Muneki. 2006. Survey on the accident caused by agricultural machinery and its protective equipment. Proceeding of Japan-Korea joint seminar on the safety of agricultural machinery: 135-159

Waters, T. R., V. Putz-Anderson, A. Grag, A. and LJ. Fine. 1993 Revised NIOSH equation for the design and evaluation of manual lifting tasks. Ergonomics 36(7): 749-776 